\title{
Perceptions of asthma among physicians: an exploratory study with the ISAAC video
}

\author{
D. Van Sickle
}

ABSTRACT: The current study examined the perception and interpretation of asthma symptoms among practitioners using standardised audiovisual presentations of asthma.

Two groups of practitioners $(n=70)$ in Chennai, India, were shown the International Study of Asthma and Allergies in Childhood (ISAAC) video questionnaire and asked to describe the symptoms and signs they observed and to identify possible diagnoses for each presentation.

The number of practitioners who correctly described the principal symptom(s) of asthma depicted in the five video sequences ranged from $26.1 \%$ for scene 5 (wheezing and dyspnoea), to $\mathbf{9 4 . 2} \%$ for scene 4 (nocturnal cough). The number who identified asthma as a possible cause of the presentations ranged from $17.4 \%$ for scene 4 , to $67.1 \%$ for scene 2 (wheeze after exercise). Practitioners with postgraduate medical education were significantly more likely to identify asthma as a possible cause of the presentations, as were practitioners with postgraduate training in respiratory diseases.

In conclusion, the perceptions of asthma and asthma symptoms among many physicians in Chennai, India, do not match the presentations of asthma depicted in the International Study of Asthma and Allergies in Childhood (ISAAC) video. These differences may be limiting the diagnosis and apparent prevalence of asthma, and suggest the need for additional attention to asthma in the education and training of practitioners in India.

KEYWORDS: Asthma, classification, diagnosis, India, International Study of Asthma and Allergies in Childhood (ISAAC), labelling

$\mathbf{M}$ any epidemiological studies rely on reported symptoms of asthma and diagnosis of asthma as a proxy for disease status. As a result, regional differences in the perception of asthma symptoms and their clinical interpretation may play an important role in the apparent patterns of disease prevalence. In addition, artefactual changes in asthma prevalence may arise from changes over time in the perception and interpretation of symptoms, and differences in the proportion of the population with symptoms labelled as asthma [1-5].

Populations in India have previously reported some of the lowest prevalence of diagnosed asthma and asthma symptoms in the world [69]. However, recent reports suggest that the prevalence may be increasing, particularly among urban residents [10, 11]. In addition, substantial variability remains between Indian communities in the prevalence of asthma and in the percentage of symptomatic individuals with a diagnosis of the disease [6, 8, 9]. Although increases in the popular and professional awareness of asthma may be affecting the proportion of individuals with a diagnosis, little is known about how practitioners in India view the set of symptoms that characterise asthma, or how they describe and label these symptoms.

This research examined perceptions and interpretation of asthma and asthma symptoms among a sample of physicians in an Indian city using the standardised audiovisual representations of asthma depicted in the International Study of Asthma and Allergies in Childhood (ISAAC) video questionnaire.

\section{METHODS}

Video instrument

The ISAAC video questionnaire (AVQ 3.0; Otago University, Dunedin, New Zealand) was developed by the Wellington Asthma Research Group to be a standardised methodology for determining the prevalence of asthma in children [12, 13]. By showing, rather than describing, symptoms of asthma, the video was expected to minimise the effect of language, culture, literacy and interview technique $[12,13]$. To date, the ISAAC video questionnaire has been used in $>40$ countries to assess the prevalence of asthma [8,9]. In the international version of the video, young adults
AFFILIATIONS

Dept of Anthropology, University of Arizona, Tucson, AZ, USA

CORRESPONDENCE

D. Van Sickle

Air Pollution and Respiratory Health Branch

Centers for Disease Control and Prevention

1600 Clifton Rd NE

MS E-17

Atlanta

GA 30333

USA

Fax: 14044981088

E-mail: dvansickle@cdc.gov

Received

March 082005

Accepted after revision:

June 012005

SUPPORT STATEMENT

The author has no financial interest in any of the topics, products or methodologies described in this paper. This research was supported entirely by a grant from the National Science Foundation (BCS-0001494), Arlington, VA, USA. 
from a variety of ethnic backgrounds can be seen and heard manifesting different symptoms of asthma during a set of five short (25 s) sequences. The sequences display a female Caucasian seated at a desk in an office with moderate wheezing at rest, a young Maori male with wheezing after jogging along a wooded trail, a young Asian male waking at night with wheezing, a young Caucasian female waking at night with coughing, and an Indian female with a severe attack of asthma with wheezing and dyspnoea. Further information about the development, validation and utilisation of the video questionnaire has been published elsewhere $[8,9,14]$.

\section{Participants}

In 2002, two groups of medical practitioners in the south Indian city of Chennai (formerly Madras) were asked to participate in an epidemiological study. An initial purposive sample of 25 practitioners was selected from the Chennai telephone directory for individual interviews. This group was chosen specifically to reflect a range of medical training and specialties, clinic types and sizes, and diverse geographical and socio-economic neighbourhoods in the city. A second, convenience sample of practitioners $(n=52)$ attending a continuing education seminar on the pharmacological management of a variety of acute respiratory emergencies was also recruited.

\section{Interviews and questionnaire}

Physicians who agreed to participate in individual interviews were met in their office, where they viewed the ISAAC video on a portable digital video player and took part in a semistructured interview. Physicians from the seminar who agreed to participate remained after the lecture to watch the ISAAC video as a group and answer the same questions on a preprinted questionnaire. The video was screened using a liquid crystal display projector, and the audio was directly amplified via the public-address system used for the lecture. The same investigator and assistant conducted all interviews and the seminar survey in order to assure the quality and comparability of the video image and sound level for all participants.

At the conclusion of each scene, the investigator paused the video and asked participants to describe (or note) the signs and symptoms they observed and to list the disease(s) they considered to be possible causes of the presentation. No limits or restrictions were placed on the number or nature of their responses. Neither group of practitioners was informed in advance that the video was an instrument used in asthma epidemiology, nor that the purpose of the study involved asthma in any way.

Practitioners were free to respond in English or Tamil, the local Indian language. A native Tamil-speaking assistant was present at all times to interpret; however, all interviews were conducted in English, and no written responses in Tamil were received on the printed questionnaire. While equivalent terms for common asthma symptoms (including wheeze, cough and dyspnoea) exist in Tamil, English is the language of medical education in India, and practitioners use English terms to refer to symptoms throughout their training and in daily clinical practice.

The interviews averaged $60 \mathrm{~min}$ in length, and followed a semi-structured format with a prepared, ordered list of questions. Each interview was tape-recorded with the explicit permission of the practitioner and transcribed verbatim. Transcripts of the interviews were analysed using qualitative software (TAMS Analyzer; May Day Softworks, Akron, $\mathrm{OH}$ USA). Details from the interviews were abstracted and combined with the results of the survey for analysis.

\section{Statistical analysis}

Analyses of dichotomous data were performed using the Chisquared test ( $>5$ observations in all cells) or Fisher's exact test ( $\leqslant 5$ observations in $\geqslant 1$ cell). Ordinal data were compared using the Chi-squared test for trend.

This research was approved by the Human Subjects Committee at the University of Arizona (Tucson, AZ, USA) and the Government of India Ministry of Human Resource Development (New Delhi).

\section{RESULTS}

\section{Study population}

A total of 22 practitioners (88\%) agreed to participate in individual interviews, which were conducted in their clinics. An additional 48 practitioners (92.3\%) attending the continuing education seminar viewed the video and completed the questionnaire survey. Table 1 shows the demographic and

\begin{tabular}{|c|c|c|c|}
\hline \multirow[t]{2}{*}{ TABLE 1} & \multirow[b]{2}{*}{ Interview } & \multirow[b]{2}{*}{ Questionnaire } & \multirow[b]{2}{*}{ Combined } \\
\hline & & & \\
\hline Practitioners & 22 & 48 & 70 \\
\hline \multicolumn{4}{|l|}{ Age } \\
\hline Yrs & $47.3 \pm 11.9$ & $36.4 \pm 10.7$ & $39.8 \pm 12.1$ \\
\hline Range & $27-76$ & $25-65$ & $25-76$ \\
\hline Males & $15(68.2)$ & $43(89.6)$ & $58(82.9)$ \\
\hline \multicolumn{4}{|l|}{ Training } \\
\hline MBBS & $8(36.4)$ & 19 (39.6) & 27 (38.6) \\
\hline MBBS + Diploma & $7(31.8)$ & $13(27.1)$ & 20 (28.6) \\
\hline $\mathrm{MD}$ & $7(31.8)$ & $16(33.3)$ & $23(32.9)$ \\
\hline \multicolumn{4}{|l|}{ Specialisation \# } \\
\hline None" & $8(36.4)$ & 19 (39.6) & 27 (38.6) \\
\hline Respiratory & $4(18.2)$ & $9(18.8)$ & $13(18.6)$ \\
\hline Paediatrics & $6(27.3)$ & $3(6.3)$ & $9(12.9)$ \\
\hline Medicine & $1(4.5)$ & $5(10.4)$ & $6(8.6)$ \\
\hline Emergency & & $3(6.3)$ & $3(4.3)$ \\
\hline Other & $3(13.6)$ & $9(18.8)$ & $12(17.1)$ \\
\hline \multicolumn{4}{|l|}{$\begin{array}{l}\text { Current clinical } \\
\text { setting(s) }\end{array}$} \\
\hline Private clinic & $15(68.2)$ & $27(56.3)$ & $42(60)$ \\
\hline Private hospital & $5(22.7)$ & $20(41.7)$ & 25 (35.7) \\
\hline $\begin{array}{l}\text { Government health } \\
\text { centre }\end{array}$ & $3(13.6)$ & $8(16.7)$ & $11(15.7)$ \\
\hline Private nursing home & $3(13.6)$ & $6(12.5)$ & $9(12.9)$ \\
\hline Other & & $2(4.2)$ & $2(2.9)$ \\
\hline
\end{tabular}

Data are presented as $n$, mean \pm SD and $n$ (\%). MBBS: Bachelor of Medicine/ Bachelor of Surgery; MD: Doctor of Medicine. ${ }^{*}$ : i.e. postgraduate training; $"$ : i.e. general practitioner; ${ }^{+}$: practitioners could report more than one current clinical setting. 
professional characteristics of the two groups of participants. More than 80 per cent of the participants were male. Although the average age of the practitioners who participated in the questionnaire survey was significantly younger than that of those who were interviewed, the groups were otherwise comparable. A total of 27 individuals $(38.6 \%)$ had completed $4 \mathrm{yrs}$ of graduate medical education and $1 \mathrm{yr}$ of internship, and received the Bachelor of Medicine/Bachelor of Surgery (MBBS) degree. Twenty participants (28.6\%) had completed an additional 2 yrs of postgraduate training and been awarded a postgraduate diploma. The remaining 23 individuals $(32.9 \%)$ had completed 3 yrs of postgraduate training and held the postgraduate Doctor of Medicine (MD) degree. Overall, 18\% of the practitioners reported postgraduate training in respiratory diseases. On average, practitioners reported daily contact with 35 patients and estimated that one quarter of them had symptoms resembling those of an individual in at least one of the five video sequences.

\section{Symptoms}

The number of practitioners who correctly described the principal symptom(s) of asthma illustrated by the sequences ranged from $26.1 \%$ for scene 5 , demonstrating both wheezing and dyspnoea, to $94.2 \%$ for scene 4 , depicting cough at night (table 2). A substantial percentage of practitioners did not identify wheeze during the four scenes in which it was featured. For example, only one third of practitioners noted wheeze in scene 5, which was intended to represent an acute exacerbation with wheezing and dyspnoea. Identification of the symptom(s) of asthma in the five sequences was not significantly associated with the medical degree of the practitioner (MBBS, MBBS and diploma, or MD) or with a history of postgraduate training in respiratory disease. There was no significant difference between practitioners who participated in individual interviews and practitioners who participated at the seminar in the proportion identifying the featured asthma symptom(s).

\begin{tabular}{|c|c|c|c|c|}
\hline TABLE 2 & \multicolumn{4}{|c|}{$\begin{array}{l}\text { Number of practitioners, by type of participation, } \\
\text { who identified the primary symptom(s) of asthma } \\
\text { depicted in the International Study of Asthma } \\
\text { and Allergies in Childhood (ISAAC) video } \\
\text { sequences }\end{array}$} \\
\hline $\begin{array}{c}\text { Scene } \\
\text { No. }\end{array}$ & Scene description & Interview $w^{\#}$ & Questionnaire & Combined $^{+}$ \\
\hline 1 & Wheeze at rest & $9(40.9)$ & $26(55.3)$ & $35(50.7)$ \\
\hline 2 & Wheeze with exercise & $15(68.2)$ & $25(52.1)$ & $40(57.1)$ \\
\hline 3 & Nocturnal wheeze & $11(50)$ & $22(45.8)$ & $33(47.1)$ \\
\hline 4 & Nocturnal cough & $21(95.4)$ & 44 (93.6) & $65(94.2)$ \\
\hline \multirow[t]{3}{*}{5} & Dyspnoea $^{\S}$ and wheeze & $4(18.2)$ & $14(29.8)$ & $18(26.1)$ \\
\hline & Dyspnoea $^{\S}$ alone & $13(59.1)$ & $39(83)$ & $52(75.4)$ \\
\hline & Wheeze alone & $7(31.8)$ & $16(34)$ & $23(33.3)$ \\
\hline \multicolumn{5}{|c|}{ 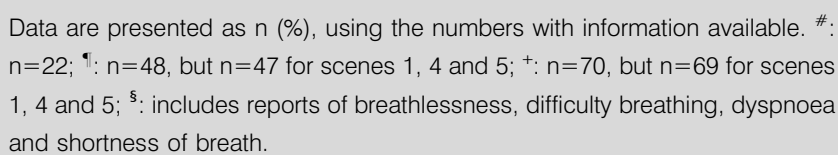 } \\
\hline
\end{tabular}

Practitioners reported a wide range of symptoms for each of the five video sequences. The mean \pm SD number of symptoms identified by the entire group of practitioners for the five scenes was $19.8 \pm 2.8$, with a range of 16-23. Individually, practitioners reported an average of two symptoms per scene. Dyspnoea (as described by terms such as breathlessness, dyspnoea, difficulty breathing and shortness of breath) was the most frequent symptom reported for three of the five scenes and the most common symptom identified overall. Cough was noted by the second largest number of practitioners overall, largely because it was commonly identified even when it represented an incidental part of the presentation, as in the first scene.

\section{Diagnostic interpretation}

The number of practitioners who identified asthma as a possible cause of the presentation ranged from $17.4 \%$ for scene 4 , featuring nocturnal cough, to $67.1 \%$ for scene 2 , depicting wheeze after exercise (table 3 ). While $7.1 \%$ of practitioners suggested asthma for all five scenes, $10 \%$ of practitioners did not consider asthma a possible cause of any of the sequences. The proportion of practitioners who identified asthma as a possible cause of the presentations in the video sequences did not differ significantly between interview and questionnaire groups.

Practitioners with postgraduate medical education were significantly more likely to report that the scenes might be asthma related. Overall, practitioners with postgraduate MD degrees identified asthma as a possible cause of $62.6 \%$ of the scenes, followed by practitioners with MBBS degrees and postgraduate diplomas at $43.7 \%$, and practitioners with MBBS degrees at $36.1 \%(p<0.001)$. In addition, practitioners with postgraduate training in respiratory diseases were significantly more likely to identify asthma as a possible cause of the video sequences when compared to practitioners with equivalent training in another topic area (odds ratio (OR) 3.08; 95\% confidence interval (CI) 1.59-6.1; $\mathrm{p}<0.001$ ).

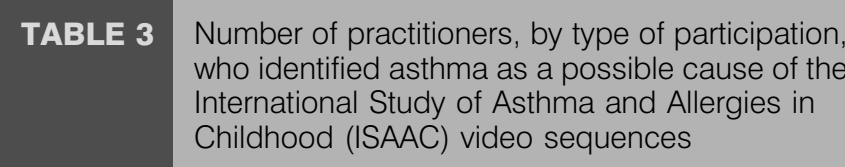

\begin{tabular}{lcrcc}
$\begin{array}{l}\text { Scene } \\
\text { No. }\end{array}$ & $\begin{array}{c}\text { Scene } \\
\text { description }\end{array}$ & Interview $^{\#}$ & Questionnaire & Combined $^{+}$ \\
\hline $\mathbf{1}$ & Wheeze at rest & $5(22.7)$ & $20(42.5)$ & $25(36.2)$ \\
$\mathbf{2}$ & Wheeze with exercise & $14(63.6)$ & $33(68.7)$ & $47(67.1)$ \\
$\mathbf{3}$ & Nocturnal wheeze & $12(54.5)$ & $23(47.9)$ & $35(50)$ \\
$\mathbf{4}$ & Nocturnal cough & $5(22.7)$ & $7(14.9)$ & $12(17.4)$ \\
$\mathbf{5}$ & Acute exacerbation & $12(54.5)$ & $32(68.1)$ & $44(63.8)$ \\
& with dyspnoea and & & & \\
& wheeze & &
\end{tabular}

Data are presented as $n(\%)$, using the numbers with information available. ${ }^{*}$. $n=22 ; \because n=48$, but $n=47$ for scenes 1,4 and $5 ;^{+}: n=70$, but $n=69$ for scenes 1,4 and 5 . 


\begin{tabular}{|c|c|c|c|c|c|}
\hline \multirow{2}{*}{$\begin{array}{l}\text { TABLE } 4 \\
\text { Scene No. }\end{array}$} & \multicolumn{5}{|c|}{$\begin{array}{l}\text { Concordance between symptom identification and asthma interpretation for each of the International Study of Asthma } \\
\text { and Allergies in Childhood (ISAAC) video sequences }\end{array}$} \\
\hline & $\begin{array}{c}\text { Scene } \\
\text { description }\end{array}$ & $\begin{array}{c}\text { PS } \\
\text { identified/asthma } \\
\text { suggested }\end{array}$ & $\begin{array}{c}\text { PS } \\
\text { identified/asthma } \\
\text { not suggested }\end{array}$ & $\begin{array}{c}\text { PS } \\
\text { not identified/asthma } \\
\text { suggested }\end{array}$ & $\begin{array}{c}\text { PS } \\
\text { not identified/asthma } \\
\text { not suggested }\end{array}$ \\
\hline 1 & Wheeze at rest & $18(26.1)$ & $17(24.6)$ & $7(10.1)$ & 27 (39.1) \\
\hline 3 & Nocturnal wheeze & $21(30)$ & $12(17.1)$ & $14(20)$ & $23(32.9)$ \\
\hline 4 & Nocturnal cough & $12(17.4)$ & $53(76.8)$ & & $4(5.8)$ \\
\hline \multirow[t]{3}{*}{$5^{\#}$} & Dyspnoea and wheeze & $14(20.3)$ & $4(5.8)$ & $30(43.5)$ & $21(30.4)$ \\
\hline & Dyspnoea" alone & 34 (49.3) & $18(26.1)$ & $10(14.5)$ & $7(10.1)$ \\
\hline & Wheeze alone & $18(26.1)$ & $5(7.3)$ & $26(37.7)$ & $20(28.9)$ \\
\hline
\end{tabular}

Data are presented as n (\%). PS: primary symptom(s). " : acute exacerbation; ": includes reports of breathlessness, difficulty breathing, dyspnoea and shortness of breath.

Although asthma was the most frequently suggested diagnostic label for four of the five scenes, practitioners reported a combined total of 42 other diagnostic labels for the five scenes, suggesting widespread variation in the interpretation of the video. Aside from asthma, the most common interpretations for the five sequences overall, in frequency of occurrence, were bronchitis and respiratory tract infections (including pneumonia), cardiovascular disease, chronic obstructive pulmonary disease, tuberculosis, airway obstruction and pulmonary oedema.

Table 4 summarises the concordance between identification of the featured symptom(s) and interpretation of the scene as asthma related. Overall, the odds that practitioners who identified the symptoms depicted in the scenes would identify asthma as a possible cause of the presentations were 1.8 times the odds of those who did not report the symptom(s) of asthma (95\% CI 1.12-3.04; $p=0.011)$. In addition, practitioners who identified wheeze in either of the first two scenes were significantly more likely to attribute the presentations to asthma than practitioners who did not report wheeze (scene 1: OR (95\% CI) 4.1 (1.27-13.9), $\mathrm{p}=0.007$; scene 2: 4 (1.24-13.27), $\mathrm{p}=0.008)$. Nevertheless, a sizeable proportion of the practitioners labelled the first three scenes as asthma related, despite not identifying the principal symptom of wheeze. In these cases, observations of dyspnoea closely predicted interpretation of the scene as asthma related. Of the practitioners who identified scenes 1, 2 and 3 as asthma related but did not report wheeze, 85.7, 87.5 and $85.7 \%$, respectively, did report dyspnoea. Similarly, more than twice as many practitioners who reported dyspnoea in scene 5 attributed the scene to asthma.

\section{DISCUSSION}

In the current study, a significant number of practitioners overlooked the primary symptoms of asthma depicted in many of the ISAAC video sequences and did not identify asthma as a possible cause of the presentations. Of the symptoms highlighted in the scenes, practitioners were least likely to identify wheeze, whereas scenes featuring cough were least likely to be attributed to asthma. Overall, practitioners who reported the featured symptoms of asthma were more likely to identify asthma as a possible cause of the video sequence. Although there were no significant differences in the proportion identifying asthma symptoms, practitioners with postgraduate medical education and practitioners with training in respiratory diseases were significantly more likely to identify asthma as a possible cause of the video sequences.

The results of the present study suggest that many practicing clinicians in India differ in the perception and interpretation of common asthma symptoms depicted in the ISAAC video. This finding may account for the low rates of reported asthma observed in epidemiological studies conducted in Chennai and other parts of India, and suggests that rates of diagnosed asthma among these populations underestimate the true burden of disease. In addition, regional patterns in the perception of symptoms such as cough, dyspnoea and wheeze, and their attribution to asthma, may explain some of the variability among Indian communities in the reported prevalence of asthma and in the percentage of symptomatic individuals with a diagnosis of the disease $[6,8,9]$.

The variability in the perception and interpretation of asthma symptoms among this group of practitioners is consistent with previous studies reporting that clinicians often disagree on the presence or absence of asthma-related respiratory signs [1517], and vary in the preferred terms for descriptions of lung sounds in asthma [18]. In one study, practitioners who differed from their colleagues in the observation of a clinical sign were more likely to make inaccurate diagnoses [17]. Another study found paediatric asthma specialists used different information in reaching their diagnoses and varied significantly when classifying the severity of standardised descriptions of patients with asthma [19]. In addition, symptoms such as cough have been shown to have changing clinical relevance to a diagnosis of asthma [15]. In the current study, recognition of wheeze and dyspnoea in the video sequences best predicted whether the practitioner attributed the presentation to asthma. By demonstrating typical presentations of asthma, including those characterised by cough, the ISAAC video may be useful in training practitioners to recognise common symptoms of asthma and consider it as a possible diagnosis. 
The results of the present study suggest that, in India and other developing country settings, the local burden of other respiratory morbidity, with signs and symptoms that overlap with asthma, may complicate the ability of practitioners to recognise certain typical manifestations of asthma. These findings may partly explain why international comparisons have found differences in rates of diagnosed asthma between countries to be much greater than differences in rates of reported asthma symptoms [20]. In fact, while symptoms are sensitive for the presence of asthma, they are relatively nonspecific, and misdiagnosis and underdiagnosis of asthma in both children and adults is common throughout the world [21]. For example, epidemiological studies conducted in India and other developing countries show that a significant percentage of children with asthma are diagnosed with recurrent pneumonia [22-25]. In the current study, a large percentage of participants attributed the presentations depicted in the video sequences to bronchitis and other respiratory tract infections. This suggests that the pattern of respiratory morbidity in the Indian population may influence the signs and symptoms practitioners emphasise in their assessments of patients, and their perception and interpretation of asthma-related symptoms. For example, practitioners in India may be unlikely to attribute cough to asthma as long as other causes of cough remain more common than asthma in the setting. Nevertheless, as the popular and professional awareness of asthma expands in India, future increases in the prevalence of diagnosed asthma are likely to result, in part, from the assignment of the diagnosis of asthma to individuals previously labelled with bronchitis and respiratory tract infections and to individuals with pre-existing but undiagnosed asthma [26].

The current study reports the perceptions of a convenience sample of practitioners attending a continuing education seminar and a purposive sample of practitioners selected to reflect a diversity of backgrounds and clinical experience. Although comparable, the groups were not intended, either separately or jointly, to be a representative sample of the population of practicing Indian physicians in the urban area of Chennai. However, because there is no mandatory system of continuing education and re-licensure in India, the sample of practitioners contacted at the continuing education seminar represents a self-selected group likely to be more knowledgeable about respiratory disease than the population of Indian physicians at large. Nevertheless, the aim of this research was not to estimate the proportion of practitioners in the community who identified asthma symptoms, but to access a diverse sample of participants in order to assess the level of agreement between the ISAAC video and practitioner perceptions and interpretations of asthma symptoms.

Although the current study is among the first to use the ISAAC video to examine practitioner perceptions of asthma and asthma symptoms, several findings support the internal validity of the method. In particular, the similar results obtained from interview and questionnaire groups suggest that the video produced valid and comparable information about practitioner perceptions of asthma. In addition, the significant and consistent misperception of the video sequences observed among these groups of practitioners suggests that the video captured patterns of misperception related to contextual factors, such as the burden of disease in the community or medical education and practice. For example, practitioners with more training were consistently more likely to identify asthma as a possible cause of the video sequences. Finally, the limited identification of some symptoms in this study does not appear to be the result of a lack of familiarity with the terms used to describe the symptoms. Although wheeze was the least commonly identified symptom, $92.9 \%$ of practitioners used a form of the English term "wheeze" at some point in their interview or on their questionnaire.

In conclusion, while rising rates of asthma in developed countries prompted study of the contribution of changing diagnostic practices and labelling [5, 26-29], to date, similar studies have not been undertaken in developing countries. Although clearly an exploratory study, this research has identified a method for and provided initial evidence that further investigation of practitioner perceptions of asthma in developing country settings is warranted. Additional studies using representative samples of practitioners are required to understand what factors contribute to the misperception and misinterpretation of asthma symptoms, and to identify strategies to improve the diagnosis and management of asthma among practitioners facing a different spectrum of respiratory illness.

\section{Conclusions}

The study demonstrates that a significant portion of practitioners in the Indian city of Chennai who viewed the International Study of Asthma and Allergies in Childhood (ISAAC) video sequences of asthma as part of an interview or questionnaire survey did not recognise the symptoms of asthma or identify asthma as a possible cause of the presentations. The observed patterns in the perception and interpretation of asthma symptoms among these groups of practitioners suggests that medical providers in India could, over time, become more aware of the symptoms of asthma and more likely to assign the diagnosis of asthma to patients. As a result, estimates of asthma prevalence derived from reports of diagnosed asthma could be affected by the general setting in which the instruments are used [30]. As DODGE and Burrows [31] suggested, "the epidemiology of asthma is a reflection of the diagnostic habits of physicians in the locale, as well as an indicator of the frequency of a specific syndrome." Epidemiological studies of asthma prevalence in developing country settings should consider the burden of respiratory diseases with similar symptomatology and address the potential impact on prevalence rates of changes in the professional awareness of asthma and asthma symptoms. Use of the International Study of Asthma and Allergies in Childhood (ISAAC) video in the education and training of practitioners in developing countries may help to improve recognition of asthma symptoms and the diagnosis and management of asthma [32, 33].

\section{REFERENCES}

1 Chinn S, Jarvis D, Burney $\mathrm{P}$, et al. Increase in diagnosed asthma but not in symptoms in the European Community Respiratory Health Survey. Thorax 2004; 59: 646-651. 
2 Wieringa $\mathrm{MH}$, Vermeire PA, Brunekreef B, Weyler JJ. Increased occurrence of asthma and allergy: critical appraisal of studies using allergic sensitization, bronchial hyper-responsiveness and lung function measurements. Clin Exp Allergy 2001; 31: 1553-1563.

3 Magnus P, Jaakkola JJK. Secular trend in the occurrence of asthma among children and young adults: critical appraisal of repeated cross sectional studies. BMJ 1997; 314: 1795-1799.

4 Gergen PJ, Weiss KB. Changing patterns of asthma hospitalization among children: 1979 to 1987. JAMA 1990; 264: 1688-1692.

5 Hill R, Williams J, Tattersfield A, Britton J. Change in use of asthma as a diagnostic label for wheezing illness in schoolchildren. BMJ 1989; 299: 898.

6 Chowgule RV, Shetye VM, Parmar JR, et al. Prevalence of respiratory symptoms, bronchial hyperreactivity, and asthma in a megacity. Results of the European Community Respiratory Health Survey in Mumbai (Bombay). Am J Respir Crit Care Med 1998; 158: 547-554.

7 European Community Respiratory Health Survey (ECRHS). Variations in the prevalence of respiratory symptoms, self-reported asthma attacks, and use of asthma medication in the European Community Respiratory Health Survey (ECRHS). Eur Respir J 1996; 9: 687-695.

8 The International Study of Asthma and Allergies in Childhood (ISAAC) Steering Committee. Worldwide variation in prevalence of symptoms of asthma, allergic rhinoconjunctivitis, and atopic eczema: ISAAC. Lancet 1998; 351: 1225-1232.

9 The International Study of Asthma and Allergies in Childhood (ISAAC) Steering Committee. Worldwide variations in prevalence of asthma symptoms: the International Study of Asthma and Allergies in Childhood (ISAAC). Eur Respir J 1998; 12: 315-335.

10 Chakravarthy S, Singh RB, Swaminathan S, Venkatesan P. Prevalence of asthma in urban and rural children in Tamil Nadu. Natl Med J India 2002; 15: 260-226.

11 Chhabra SK, Gupta CK, Chhabra P, Rajpal S. Risk factors for development of bronchial asthma in children in Delhi. Ann Allergy Asthma Immunol 1999; 83: 385-390.

12 Shaw RA, Crane J, O’Donnell TV, Lewis ME, Stewart B, Beasley Rl. The use of a videotaped questionnaire for studying asthma prevalence. A pilot study among New Zealand adolescents. Med J Aust 1992; 157: 311-314.

13 Shaw RA, Crane J, Pearce N, et al. Comparison of a video questionnaire with the IUATLD written questionnaire for measuring asthma prevalence. Clin Exp Allergy 1992; 22: 561-568.

14 Asher MI, Keil U, Anderson HR, et al. International study of asthma and allergies in childhood (ISAAC): rationale and methods. Eur Respir J 1995; 8: 483-491.

15 Kelly YJ, Brabin BJ, Milligan PJ, Reid JA, Heaf D, Pearson MG. Clinical significance of cough and wheeze in the diagnosis of asthma. Arch Dis Child 1996; 75: 489-493.
$16 \mathrm{Li} \mathrm{JT}, \mathrm{O}^{\prime}$ Connell EJ. Clinical evaluation of asthma. Ann Allergy Asthma Immunol 1996; 76: 1-13.

17 Spiteri MA, Cook DG, Clarke SW. Reliability of eliciting physical signs in examination of the chest. Lancet 1988; 1: 873-875.

18 Pasterkamp H, Montgomery M, Wiebicke W. Nomenclature used by health care professionals to describe breath sounds in asthma. Chest 1988; 92: 346-352.

19 Baker KM, Brand DA, Hen J. Classifying asthma: disagreement among specialists. Chest 2003; 124: 2156-2163.

20 Pearce N, Weiland S, Keil U, et al. Self-reported prevalence of asthma symptoms in children in Australia, England, Germany and New Zealand: an international comparison using the ISAAC protocol. Eur Respir J 1993; 6: 1455-1461.

21 NIH. Global Strategy for Asthma Management and Prevention: National Institutes of Health. Bethesda, National Heart, Lung, and Blood Institute, 2002.

22 Ciftci E, Gunes M, Koksal Y, Ince E, Dogru U. Underlying causes of recurrent pneumonia in Turkish children in a university hospital. J Trop Pediatr 2003; 49: 212-215.

23 Eigen H, Laughlin JJ, Homrighausen J. Recurrent pneumonia in children and its relationship to bronchial hyperreactivity. Pediatrics 1982; 70: 698-704.

24 Heffelfinger JD, Davis TE, Gebrian B, Bordeau R, Schwartz B, Dowell SF. Evaluation of children with recurrent pneumonia diagnosed by World Health Organization criteria. Pediatr Infect Dis J 2002; 21: 108-112.

25 Lodha R, Puranik M, Natchu UC, Kabra SK. Recurrent pneumonia in children: clinical profile and underlying causes. Acta Paediatr 1988; 91: 1170-1173.

26 Burney PG, Chinn S, Rona RJ. Has the prevalence of asthma increased in children? Evidence from the national study of health and growth 1973-86. BMJ 1990; 300: 1306-1310.

27 Gergen PJ, Weiss KB. The increasing problem of asthma in the United States. Am Rev Respir Dis 1992; 146: 823-824.

28 Britton J. Asthma's changing prevalence. BMJ 1992; 304: 857-858.

29 Nystad W, Magnus P, Gulsvik A, Skarpaas IJ, Carlsen KH. Changing prevalence of asthma in school children: evidence for diagnostic changes in asthma in two surveys 13 years apart. Eur Respir J 1997; 10: 1045-1051.

30 Fuso L, de Rosa M, Corbo GM, et al. Repeatability of the ISAAC video questionnaire and its accuracy against a clinical diagnosis of asthma. Respir Med 2000; 94: 397-403.

31 Dodge RR, Burrows B. The prevalence and incidence of asthma and asthma-like symptoms in a general population sample. Am Rev Respir Dis 1980; 122: 567-575.

32 Singh RB. Asthma in India: applying science to reality. Clin Exp Allergy 2004; 34: 686-688.

33 Nelson EA, Olukoya A, Scherpbier RW. Towards an integrated approach to lung health in adolescents in developing countries. Ann Trop Paediatr 2004; 24: 117-131. 